\title{
A tannin-based agent for coagulation and flocculation of municipal wastewater: Chemical composition, performance assessment compared to Polyaluminum chloride, and application in a pilot plant
}

\begin{abstract}
Chemical composition and flocculation efficiency were investigated for a commercially produced tannin - based coagulant and flocculant (Tanfloc). The results of Fourier Transform Infrared Spectroscopy (FTIR) and Energy Dispersive Spectroscopy (EDX) confirmed what claimed about the chemical composition of Tanfloc. For moderate polluted municipal wastewater investigated in both jar test and pilot plant, Tanfloc showed high turbidity removal efficiency of approximately 90\%, while removal efficiencies of BOD5 and COD were around $60 \%$. According to floc size distribution, Tanfloc was able to show distinct performance compared to Polyaluminum chloride (PAC). While $90 \%$ of flocs produced by Tanfloc were smaller than 144 micron, they were smaller than 96 micron for PAC. Practically, zeta potential measurement showed the cationic nature of Tanfloc and suggested coincidence of charge neutralization and another flocculation mechanism (bridging or patch flocculation). Sludge Volumetric Index (SVI) measurements were in agreement with the numbers found in the literature, and they were less than $160 \mathrm{~mL} / \mathrm{g}$. Calcium cation as flocculation aid showed significant improvement of flocculation efficiency compared to other cations. Finally Tanfloc showed competing performance compared to PAC in terms of turbidity, BOD5 and COD removal, floc size and sludge characteristics.
\end{abstract}

Keyword: Coagulation; Flocculation; Municipal wastewater; Natural flocculant 
